JMSP: Jurnal Manajemen dan Supervisi Pendidikan

Volume 2 Nomor 3 Juli 2018

Tersedia Online di http://journal2.um.ac.id/index.php/jmsp/

ISSN Online : 2541-4429

\title{
PENGARUH PEMBENTUKAN TIM DAN KEPEMIMPINAN SPIRITUAL TERHADAP MOTIVASI DIRI MAHASISWA
}

\author{
Sultoni, Imam Gunawan, Tri Novia Rosalinda \\ Universitas Negeri Malang, Jalan Semarang 5 Malang 65145 \\ Email: imam.gunawan.fip@um.ac.id
}

\begin{abstract}
This research aims to determine the influence of team building and spiritual leadership on student self motivation. This research uses quantitative method. Technique of collecting research data by using questionnaire. The sample is 50 students. Sampling using quota random sampling technique. Data analysis used is multiple regression analysis. The result of research data analysis conclude that there is significant influence of team building (X1) and spiritual leadership (X2) toward student self motivation $(\mathrm{Y})$, with regression coefficient 0,653 . The regression equation formed is: $\hat{\mathrm{Y}}=10,497+0,150 \mathrm{X} 1+0,220 \mathrm{X} 2$. Effective contribution of team building variable and spiritual leadership to student self motivation is $42,6 \%$.
\end{abstract}

Keywords: team building, spiritual leadership, self motivation

\begin{abstract}
Abstrak: Penelitian ini bertujuan untuk mengetahui pengaruh pembentukan tim dan kepemimpinan spiritual terhadap motivasi diri mahasiswa. Penelitian ini menggunakan metode kuantitatif. Teknik pengumpulan data penelitian dengan menggunakan angket. Sampel penelitian berjumlah 50 orang mahasiswa. Pengambilan sampel dengan menggunakan teknik quota random sampling. Analisis data yang digunakan adalah analisis regresi ganda. Hasil analisis data penelitian menyimpulkan ada pengaruh yang signifikan variabel pembentukan tim (X1) dan kepemimpinan spiritual (X2) terhadap motivasi diri mahasiswa $(\mathrm{Y})$, dengan koefisien regresi 0,653 . Persamaan regresi yang terbentuk adalah: $\hat{Y}=10,497+0,150 \mathrm{X} 1+$ $0,220 X 2$. Sumbangan efektif variabel pembentukan tim dan kepemimpinan spiritual terhadap motivasi diri mahasiswa adalah sebesar $42,6 \%$.
\end{abstract}

Kata kunci: pembentukan tim, kepemimpinan spiritual, motivasi diri

Manusia sebagai makhluk sosial tidak dapat memenuhi kebutuhanya sendiri, sehingga ia harus bekerja sama dengan orang lain. Oleh sebab itu, kesadaran akan pentingnya saling membutuhkan orang lain harus ditanamkan kepada setiap individu. Mahasiswa sebagai insan cendekia dalam melaksanakan tugas dan tanggung jawabnya juga harus mampu bekerja sama dengan mahasiswa lain. Tentu bekerja sama yang dimaksud dalam hal ini adalah kerja sama dalam hal positif. Salah satu wahana mahasiswa untuk belajar hidup bersama dapat adalah organisasi kemahasiswaan (ormawa). Mahasiswa tidak jarang harus membentuk tim yang solid untuk dapat melaksanakan suatu kegiatan dalam rangka mencapai tujuan. Pembentukan tim (team building) yang para anggotanya memiliki visi dan misi yang sama merupakan syarat terbentuknya tim yang solid, kuat, dan berkomitmen tinggi.

Fokus utama pembentukan tim yang baik adalah: (1) kesamaan kepribadian; (2) kreativitas dan imajinasi; (3) adanya ikatan; (4) mampu kerja sama; dan (5) adanya pengalaman bersama (Ireland, dkk., 2017). Membentuk tim (team building) telah diidentifikasi sebagai metode penting untuk meningkatkan iklim psikologis di mana tim beroperasi, serta fungsi tim secara keseluruhan (Beauchamp, dkk., 2017). Pembentukan tim yang baik akan berdampak positif terhadap iklim kerja anggota organisasi (Riener dan Wiederhold, 2016). Membentuk tim dalam organisasi dapat meningkatkan motivasi kerja para anggota (Spinney, 2018; Lester, 2017). Pembentukan tim dalam organisasi dimaksudkan untuk meningkatkan keefektifan dan efisiensi organisasi dalam mencapai tujuan. Hal ini juga 
berlaku bagi ormawa yang notabene merupakan kumpulan individu yang memiliki perbedaan dan juga persamaan. Oleh sebab itu, komitmen tim dalam organisasi sangat penting dalam proses organisasi mencapai tujuan. Tak berlebihan jika Svalestuen, dkk., (2015) menyatakan bahwa pembentukan tim yang solid merupakan elemen kunci organisasi dalam mencapai tujuan.

Tim tersebut tentu akan berjalan efektif jika didukung dengan kepemimpinan yang baik. Kepemimpinan spiritual merupakan sifat-sifat kepemimpinan yang berlandaskan pada nafas bahwa manusia sebagai pemimpin yang diberikan amanah oleh Tuhan untuk mengelola kehidupan. Pembentukan tim dengan disertai variabel kepemimpinan mempengaruhi kesuksesan organisasi dalam mencapai target (Aga, dkk., 2016; Feldman, 2018; Valori dan Johnston, 2016). Tujuan kepemimpinan spiritual adalah untuk menciptakan visi dan keselarasan nilai seluruh anggota tim yang diberdayakan, dan pada level individu yang pada akhirnya untuk menumbuhkan komitmen, produktivitas organisasi, dan kesejahteraan anggota yang lebih tinggi (Fry, 2003; Fry, dkk., 2005). Kepemimpinan spiritual dengan didukung variabel iklim kerja yang baik dapat mempengaruhi signifikan motivasi diri individu dalam bekerja (Afsar, dkk., 2016). Seorang pemimpin yang sukses ialah yang memahami keinginan para anggota, mampu memberikan pencerahan untuk mencapai tujuan organisasi, dan dapat mengapresiasi setiap capaian individu agar ia terus termotivasi.

Motivasi diri yang kuat akan mendorong mahasiswa untuk mencapai tujuannya, baik tujuan individu dan tujuan organisasi. Motivasi diri mahasiswa adalah faktor pendorong yang bersumber dari dalam diri mahasiswa untuk berbuat sesuatu. Motivasi diri adalah dalam bentuknya yang paling sederhana, kekuatan yang mendorong individu untuk melakukan banyak hal. Motivasi diri itu didasarkan pada seperangkat motif independen yang dimiliki setiap individu (Silvia dan Duval, 2004). Motivasi diri adalah apa yang menyemangati seseorang; dan merupakan dorongan internal seseorang secara otonom untuk memiliki kuasa atas pilihan dan tindakannya sendiri (Silver, 2017). Motivasi diri memberikan dorongan seseorang untuk memiliki minat dalam penampilannya untuk membangun dan mempertahankan harga dirinya
(Bénabou dan Tirole, 2001). Motivasi diri, secara intuitif, merupakan stimulus yang baik untuk meningkatkan kinerja individu dalam organisasi (Pelz, 1962). Tujuan penelitian ini adalah untuk mengetahui pengaruh pembentukan tim dan kepemimpinan spiritual terhadap motivasi diri mahasiswa.

\section{METODE}

Penelitian ini menggunakan metode kuantitatif. Variabel penelitian adalah pembentukan tim (X1) dan kepemimpinan spiritual (X2) sebagai variabel prediktor, serta variabel motivasi diri mahasiswa $(\mathrm{Y})$ sebagai variabel kriterium. Teknik pengumpulan data penelitian dengan menggunakan angket tertutup. Sampel penelitian berjumlah 50 orang mahasiswa dari populasi 60 orang mahasiswa pengurus organisasi kemahasiswaan (ormawa) yang mengikuti kegiatan Pelatihan Team Building, Spiritual Leadership, dan Self Motivation Mahasiswa Fakultas Ekonomi (FE) Universitas Negeri Malang (UM). Pelatihan dilaksanakan pada hari Jumat 10 November 2017 di Aula FE UM. Pengambilan sampel dengan menggunakan teknik quota random sampling. Analisis data yang digunakan adalah analisis regresi ganda. Analisis data dengan menggunakan IBM SPSS Statistics 20.

\section{HASIL}

Hipotesis pertama yaitu tidak ada pengaruh pembentukan tim (X1) terhadap motivasi diri mahasiswa $(\mathrm{Y})$ diuji dengan analisis regresi secara parsial. Formula yang digunakan untuk menghitung seberapa besar pengaruh pembentukan tim (X1) terhadap variabel motivasi diri mahasiswa (Y) adalah rumus uji $\mathrm{t}$, dengan menggunakan taraf signifikansi 0,05 yakni H0 ditolak jika nilai signifikansi yang diperoleh sebesar $\leq 0,05$ dan $\mathrm{H} 0$ tak ditolak jika nilai signifikansi yang diperoleh sebesar $>0,05$ (Stevens, 1996; Gunawan, 2013; Gunawan, 2016). Hasil analisis regresi variabel pembentukan tim (X1) terhadap motivasi diri mahasiswa (Y) seperti pada Tabel 1. Berdasarkan Tabel 1 diketahui nilai signifikansi sebesar $0,002<0,05$ sehingga H0 ditolak, maka dapat disimpulkan ada pengaruh yang signifikan variabel pembentukan 
tim (X1) terhadap motivasi diri mahasiswa (Y). Koofisien regresi variabel pembentukan tim (X1) terhadap motivasi diri mahasiswa (Y) adalah 0,627 . Sumbangan relatif variabel pembentukan tim (X1) terhadap motivasi diri mahasiswa (Y) adalah sebesar 39,3\% (dari hasil perhitungan RSquare $\times 100=0,393 \times 100=39,3$ ).

Tabel 1 Analisis Regresi Variabel Pembentukan Tim (X1) terhadap Motivasi Diri Mahasiswa (Y)

\begin{tabular}{|c|c|c|c|c|c|c|}
\hline R & $\begin{array}{c}\text { R } \\
\text { Square }\end{array}$ & $\begin{array}{l}\text { Sum of } \\
\text { Squares }\end{array}$ & df & $\begin{array}{l}\text { Mean } \\
\text { Squares }\end{array}$ & $t$ & itg. \\
\hline 0,627 & 0,393 & 365,394 & $\begin{array}{c}1 \\
49\end{array}$ & 11,769 & 2,209 & 0,002 \\
\hline
\end{tabular}

Hipotesis kedua yaitu tidak ada pengaruh kepemimpinan spiritual (X2) terhadap motivasi diri mahasiswa (Y) diuji dengan analisis regresi secara parsial. Formula yang digunakan untuk menghitung seberapa besar pengaruh kepemimpinan spiritual (X2) terhadap variabel motivasi diri mahasiswa $(\mathrm{Y})$ adalah rumus uji $\mathrm{t}$, dengan menggunakan taraf signifikansi 0,05 yakni H0 ditolak jika nilai signifikansi yang diperoleh sebesar $\leq 0,05$ dan H0 tak ditolak jika nilai signifikansi yang diperoleh sebesar $>0,05$ (Stevens, 1996; Gunawan, 2013; Gunawan, 2016). Hasil analisis regresi variabel kepemimpinan spiritual (X2) terhadap motivasi diri mahasiswa (Y) seperti pada Tabel 2. Berdasarkan Tabel 2 diketahui nilai signifikansi sebesar 0,004 $<0,05$ sehingga $\mathrm{H} 0$ ditolak, maka dapat disimpulkan ada pengaruh yang signifikan variabel kepemimpinan spiritual (X2) terhadap motivasi diri mahasiswa (Y). Koofisien regresi variabel kepemimpinan spiritual (X2) terhadap motivasi diri mahasiswa (Y) adalah 0,456. Sumbangan relatif variabel kepemimpinan spiritual (X2) terhadap motivasi diri mahasiswa (Y) adalah sebesar 24,5\% (dari hasil perhitungan RSquare x $100=0,245 \times 100$ $=24,5)$.
Tabel 2 Analisis Regresi Variabel Kepemimpinan Spiritual (X2) terhadap Motivasi Diri Mahasiswa (Y)

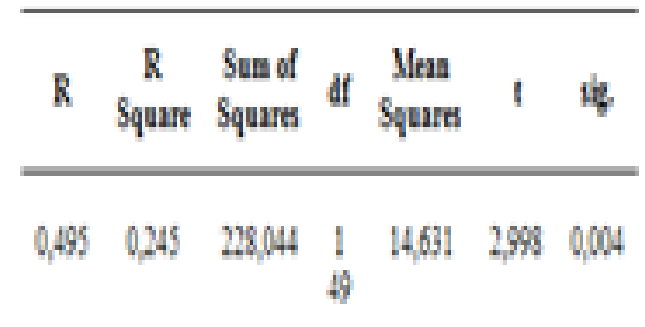

Hipotesis ketiga yaitu tidak ada pengaruh pembentukan tim (X1) dan kepemimpinan spiritual (X2) terhadap motivasi diri mahasiswa (Y) diuji dengan analisis regresi secara simultan. Formula yang digunakan untuk menghitung seberapa besar pengaruh pembentukan tim (X1) dan kepemimpinan spiritual (X2) terhadap variabel motivasi diri mahasiswa (Y) adalah rumus uji $\mathrm{F}$, dengan menggunakan taraf signifikansi 0,05 yakni $\mathrm{H} 0$ ditolak jika nilai signifikansi yang diperoleh sebesar $\leq 0,05$ dan $\mathrm{H} 0$ tak ditolak jika nilai signifikansi yang diperoleh sebesar > 0,05 (Stevens, 1996; Gunawan, 2013; Gunawan, 2016). Hasil analisis regresi variabel pembentukan tim (X1) dan kepemimpinan spiritual (X2) terhadap motivasi diri mahasiswa (Y) seperti pada Tabel 3. Berdasarkan Tabel 3 diketahui nilai signifikansi sebesar $0,000<0,05$ sehingga $\mathrm{H} 0$ ditolak, maka dapat disimpulkan ada pengaruh yang signifikan variabel pembentukan tim (X1) dan kepemimpinan spiritual (X2) terhadap motivasi diri mahasiswa (Y). Koofisien regresi variabel pembentukan tim (X1) dan kepemimpinan spiritual (X2) terhadap motivasi diri mahasiswa $(Y)$ adalah 0,653 . Sumbangan efektif variabel pembentukan tim (X1) dan kepemimpinan spiritual (X2) terhadap motivasi diri mahasiswa (Y) adalah sebesar 42,6\% (dari hasil perhitungan RSquare $\times 100=0,426 \times 100$ $=42,6)$. Sedangkan sisanya $57,4 \%$ berasal dari variabel lain. 
Tabel 3 Analisis Regresi Variabel Pembentukan Tim (X1) dan Kepemimpinan Spiritual (X2) terhadap Motivasi Diri Mahasiswa (Y)

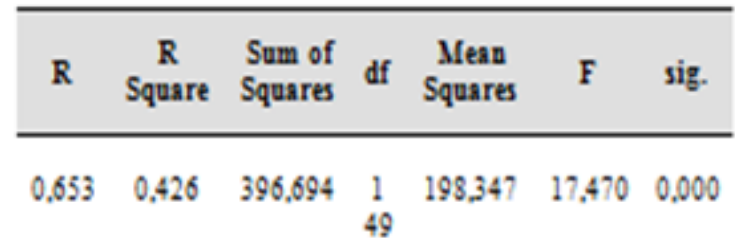

Selanjutnya berdasarkan hasil analisis regresi secara simultan dihitung persamaan regresi ganda dari tabel coefficients(a) seperti yang ditampilkan pada Tabel 4. Berdasarkan Tabel 4 dapat diketahui bahwa nilai konstanta ( $\beta 0)$ sebesar 10,497; nilai koefisien variabel pembentukan tim $(\beta 1)$ sebesar 0,150 ; dan nilai koefisien variabel kepemimpinan spiritual $(\beta 2)$ sebesar 0,220 . Jadi persamaan regresinya adalah: $\hat{\mathrm{Y}}=10,497+0,150 \mathrm{X} 1+0,220 \mathrm{X} 2$.

\section{Tabel 4 Coefficients(a)}

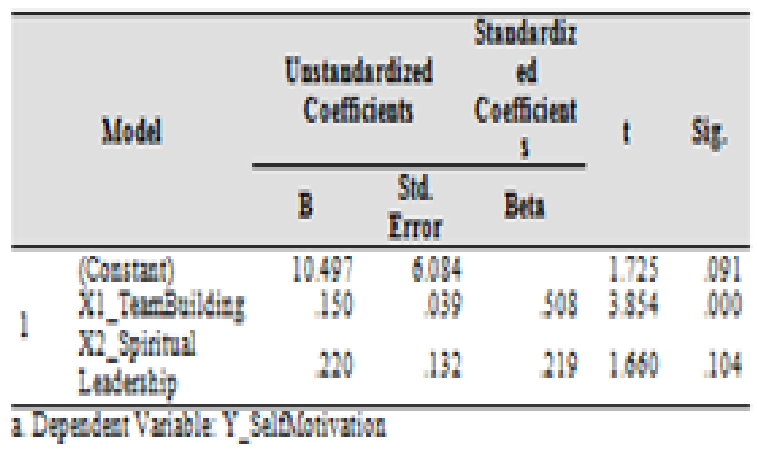

Konstanta sebesar 10,497 menyatakan bahwa jika tidak terdapatkenaikan skor dari pembentukan tim (X1) dan kepemimpinan spiritual (X2), maka skor motivasi diri mahasiswa (Y) adalah sebesar 10,497. Koefisien regresi sebesar 0,150 untuk variabel pembentukan tim (X1); dan 0,220 untuk variabel kepemimpinan spiritual (X2) menyatakan bahwa setiap penambahan satu skor pembentukan tim (X1) dan kepemimpinan spiritual (X2) akan memberikan kenaikan sebesar 0,150 dan 0,220 secara bersama-sama.

\section{PEMBAHASAN}

Berdasarkan uji hipotesis pertama, penelitian ini menyimpulkan bahwa terdapat pengaruh yang signifikan pembentukan tim terhadap motivasi diri. Hasil penelitian ini selaras dengan temuan penelitian Christian (2018) yang menyimpulkan bahwa pembentukan tim dalam organisasi dengan tujuan melaksanakan suatu program atau proyek tertentu dapat meningkatkan motivasi diri para anggota tim. Motivasi diri dan kinerja organisasi akan meningkatkan manakala anggota organisasi terkumpul dalam tim yang solid dalam melaksanakan suatu kegiatan (Peterson, 2007; Lester, 2017). Pembentukan tim yang tepat dapat meningkatkan motivasi diri anggota tim dalam bekerja (Clark, 2003).

Organisasi tentu menginginkan tingkat efisiensi dan keefektifan yang tinggi dalam mencapai tujuan. Oleh sebab itu, pemberdayaan anggota dengan didukung oleh pembentukan tim yang solid dapat mendukung hal tersebut (Burton, 2012; Kusumaningrum, dkk., 2017a). Bekerja dalam tim dapat membuat seseorang termotivasi dalam melakukan pekerjaan dengan dilandasi rasa kebersamaan dan komitmen yang tinggi (Jiang, 2010). Tim merupakan sebuah kelompok di mana individu memiliki tujuan yang sama dan di mana pekerjaan dan keterampilan setiap anggota cocok dengan orang lain (Thomas, 2004; Kusumaningrum, dkk., 2017b). Individu dalam organisasi atau kelompok saling berinteraksi, menguatkan satu sama lain, dan saling mendukung serta memotivasi.

Berdasarkan uji hipotesis kedua, penelitian ini menyimpulkan bahwa terdapat pengaruh yang signifikan kepemimpinan spiritual terhadap motivasi diri. Hasil penelitian ini selaras dengan hasil penelitian Fry dan Cohen (2009) yang menyimpulkan bahwa kepemimpinan spiritual mempengaruhi secara signifikan motivasi diri setiap individu untuk bekerja. Kepemimpinan spiritual yang didasarkan pada model motivasi diri anggota organisasi (Fry, 2003) dengan menggabungkan pemahaman anggota terhadap visi organisasi, harapan serta keyakinan, dan cinta altruis yang tinggi, dapat mempengaruhi tingkat nilai-nilai spiritualitas dan kesejahteraan spiritual individu di tempat kerja (Fry dan Cohen, 2009; Kusmintardjo dan Gunawan, 2017).

Tim akan lebih efektif jika didukung dengan kepemimpinan yang baik. Kepemimpinan dalam organisasi memiliki peran untuk mempengaruhi semua anggota organisasi untuk melaksanakan tugas dan tanggung jawabnya. Kepemimpinan yang berlandaskan pada nilai-nilai spiritualitas 
mampu mengubah sikap para pengikut (Fry, 2005; Gunawan, 2016a). Nilai-nilai yang telah lama dianggap sebagai indikator spiritual, seperti integritas, kejujuran, dan kerendahan hati, telah terbukti memiliki efek pada keberhasilan kepemimpinan (Reave, 2005; Gunawan, 2015). Nilai-nilai spiritualitas dalam kepemimpinan dapat meningkatkan motivasi diri dan kinerja individu dalam organisasi (Bodla, dkk., 2013; Vonny, dkk., 2017).

Berdasarkan uji hipotesis ketiga, penelitian ini menyimpulkan bahwa terdapat pengaruh yang signifikan pembentukan tim dan kepemimpinan spiritual terhadap motivasi diri. Hasil penelitian ini mengisyaratkan bahwa tim yang solid dengan didukung oleh kepemimpinan yang baik akan berdampak pada motivasi setiap individu dalam melaksanakan tugasnya. Setiap individu dengan memiliki motivasi diri yang tinggi dapat meningkatkan capaian kinerjanya dalam organisasi. Oleh sebab itu, seorang pemimpin harus mampu mengelola organisasi dengan tim yang solid agar organisasi dapat mencapai tujuan secara efisien (Onjoro, dkk., 2015; Gunawan, 2017). Seorang pemimpin harus memberdayakan sumber daya manusia yang dimiliki organisasi, yang di dalamnya terdapat berbagai tim, kelompok, atau divisi, dengan berlandaskan pada moral dan etika organisasi (Sweeney dan Fry, 2012; Pertiwi, dkk., 2017).

Tim yang hebat dapat memahami dan memenuhi kebutuhan para anggotanya (Bezy, 2011). Hasil penelitian ini selaras dengan pendapat Northouse (2001) dan Naidoo (2014) yang menyatakan bahwa berdasarkan perspektif etika dan nilai, para pemimpin memiliki dampak pada pembentukan dan penguatan nilai-nilai pribadi, tim, dan organisasi. Kepemimpinan yang diiringi dengan kemampuan membangun tim yang kuat, serta dengan memperhatikan motivasi diri setiap individu dalam organisasi, mampu meningkatkan motivasi, moral kerja, dan kemandirian para anggota (Bissessar, 2014; Arshad dan Abbasi, 2014). Organisasi dalam mencapai tujuannya, memerlukan tim yang solid dan kepemimpinan yang kuat sehingga hal tersebut mampu meningkatkan motivasi diri setiap individu dalam melaksanakan tugas dan tanggung jawabnya.

\section{SIMPULAN}

Berdasarkan hasil analisis data penelitian menyimpulkan ada pengaruh yang signifikan variabel pembentukan tim (X1) dan kepemimpinan spiritual (X2) terhadap motivasi diri mahasiswa $(\mathrm{Y})$. Koofisien regresi variabel pembentukan tim (X1) dan kepemimpinan spiritual (X2) terhadap motivasi diri mahasiswa (Y) adalah 0,653. Sumbangan efektif variabel pembentukan tim (X1) dan kepemimpinan spiritual (X2) terhadap motivasi diri mahasiswa (Y) adalah sebesar 42,6\%. Sedangkan sisanya $57,4 \%$ berasal dari variabel lain.

\section{DAFTAR RUJUKAN}

Afsar, B., Badir, Y., dan Kiani, U. S. 2016. Linking Spiritual Leadership and Employee ProEnvironmental Behavior: The Influence of Workplace Spirituality, Intrinsic Motivation, and Environmental Passion. Journal of Environmental Psychology, 45, 79-88.

Aga, D. A., Noorderhaven, N., dan Vallejo, B. 2016. Transformational Leadership and Project Success: The Mediating Role of Team-Building. International Journal of Project Management, 34(5), 806-818.

Arshad, A., dan Abbasi, A. S. 2014. Spiritual Leadership and Psychological Ownership: Mediating Role of Spiritual Wellbeing. Science International, 26(3), 1265-1269.

Beauchamp, M. R., McEwan, D., dan Waldhauser, K. J. 2017. Team Building: Conceptual, Methodological, and Applied Considerations. Current Opinion in Psychology, 16, 114-117.

Bénabou, R., dan Tirole, J. 2001. Self-Confidence and Personal Motivation. Pennsylvania: The University of Pennsylvania.

Bezy, K. G. 2011. An Operational Definition of Spiritual Leadership. Disertasi tidak diterbitkan. Virginia: Virginia Polytechnic Institute and State University.

Bissessar, C. 2014. Collaborative Leadership and Motivation as Examples of Education for All Goals 1, 3, 4, and 6 at Work in Seven Schools in Trinidad. Research in Comparative and International Education, 9(1), 111-125.

Bodla, M. A., Ali, H., dan Danish, R. Q. 2013. Role of Spiritual Leaders in Enhancing Employee's Performance. Journal of Basic and Applied Scientific Research, 3(3), 117-122.

Burton, K. 2012. A Study of Motivation: How to Get Your Employees Moving. Indiana: Indiana University.

Christian, K. 2018. Building Your Team. Keys to 
Running Successful Research Projects, 45, 71113.

Clark, R. E. 2003. Fostering the Work Motivation of Individuals and Teams. Performance Improvement, 42(3), 21-29.

Feldman, H. R. 2018. Identifying, Building, and Sustaining Your Leadership Team. Journal of Professional Nursing, 34(2), 87-91.

Fry, L. W. 2003. Toward a Theory of Spiritual Leadership. The Leadership Quarterly, 14(6), 693-727.

Fry, L. W. 2005. Introduction to the Leadership Quarterly Special Issue: Toward a Paradigm of Spiritual Leadership. The Leadership Quarterly, 16(5), 619-622.

Fry, L. W., dan Cohen, M. P. 2009. Spiritual Leadership as a Paradigm for Organizational Transformation and Recovery from Extended Work Hours Cultures. Journal of Business Ethics, 84, 265-278.

Fry, L. W., Vitucci, S., dan Cedillo, M. 2005. Spiritual Leadership and Army Transformation: Theory, Measurement, and Establishing a Baseline. The Leadership Quarterly, 16(5), 835-862.

Lester, E. I. A. 2017. Team Building and Motivation. Project Management, Planning and Control, 17, 369-377.

Gunawan, I. 2013. Statistika untuk Kependidikan Sekolah Dasar. Yogyakarta: Penerbit Ombak.

Gunawan, I. 2015. Values and Ethics in Educational Leadership: An Idea of Character Building of Students. Conference Proceedings Character Education in Indonesia Concepts and Applications in Primary Schools, IKIP PGRI MADIUN, hlm. 1-13.

Gunawan, I. 2016a. Model of Educational Leadership in the Implementation of Curriculum 2013. Proceedings The 4th International Conference Language, Society, and Culture in Asian Contexts (LSCAC 2016) on Cultivating and Casting Asian Diversities: Empowering the Asians, hlm. 1109-1118.

Gunawan, I. 2016b. Pengantar Statistika Inferensial. Jakarta: Rajawali Pers.

Gunawan, I. 2017. Instructional Leadership Profile of Junior High School's Principal (A Case Study of Junior High School in Malang). International Research-Based Education Journal, 1(1), 64-68.

Ireland, J. D., Deloney, L. A., Renfroe, S., dan Jambhekar, K. 2017. The Use of Team-Building Activities to Build a Better Resident. Current Problems in Diagnostic Radiology, 46(6), 399401.

Jiang, X. 2010. How to Motivate People Working in Teams? International Journal of Business and Management, 5(10), 223-229.

Kusmintardjo, dan Gunawan, I. 2017. Manajemen
Layanan Khusus. Malang: Universitas Negeri Malang, Penerbit UM Press.

Kusumaningrum, D. E., Sumarsono, R. B., dan Gunawan, I. 2017a. Pemberdayaan Tenaga Administrasi Sekolah Menengah Pertama Berbasis Pesantren. Prosiding Seminar Nasional Pendidikan: Sinergitas Keluarga, Sekolah, dan Masyarakat dalam Penguatan Pendidikan Karakter, Fakultas Ilmu Pendidikan Universitas Negeri Malang, hlm. 127-138.

Kusumaningrum, D. E., Sumarsono, R. B., dan Gunawan, I. 2017b. Problematika Pemberdayaan dan Pengembangan Sumber Daya Manusia di Sekolah Menengah Pertama Berbasis Pesantren. Ilmu Pendidikan: Jurnal Kajian Teori dan Praktik Kependidikan, 2(2): 139-150.

Naidoo, M. 2014. The Potential of Spiritual Leadership in Workplace Spirituality. Koers - Bulletin for Christian Scholarship, 79(2), 1-8.

Northouse, P. G. 2001. Leadership: Theory and Practice. Thousand Oaks: Sage Publications.

Onjoro, V., Arogo, R. B., dan Embeywa, H. E. 2015. Leadership Motivation and Mentoring Can Improve Efficiency of a Classroom Teacher and Workers in Institutions. Journal of Education and Practice, 6(15), 1-14.

Pelz, D. C. 1962. Self-Determination and SelfMotivation in Relation to Performance: A Study of Interaction Effects. Michigan: The University of Michigan.

Pertiwi, A. K., Cahyani, S. S. A., Diana, R. C., dan Gunawan, I. 2017. Kepemimpinan Berbasis Nilai dan Etika: Suatu Kajian Interaksi Simbolik Kyai dan Santri. Prosiding Seminar Nasional Pendidikan: Sinergitas Keluarga, Sekolah, dan Masyarakat dalam Penguatan Pendidikan Karakter, Fakultas Ilmu Pendidikan Universitas Negeri Malang, hlm. 1-9.

Peterson, T. M. 2007. Motivation: How to Increase Project Team Performance. Project Management Journal, 38(4), 60-69.

Reave, L. 2005. Spiritual Values and Practices Related to Leadership Effectiveness. The Leadership Quarterly, 16(5), 655-687.

Riener, G., dan Wiederhold, S. 2016. Team Building and Hidden Costs of Control. Journal of Economic Behavior \& Organization, 123, 1-18.

Silver, C. 2017. Self-Motivation: What Is It and How Do We Use It to Empower Children? (Online), (https://us.sagepub.com/sites/default/files/upmbinaries/49894_Silver__Ch1.pdf), diakses 29 Mei 2018.

Silvia, P. J., dan Duval, T. S. 2004. Self-Awareness, Self-Motives, and Self-Motivation. Dalam Wright, R. A., Greenberg, J., dan Brehm, S. S., (Eds.), Motivation and Emotion in Social Contexts: Jack Brehm's Diverse Influence on 
Contemporary Psychological Thought. Mahwah, NJ: Erlbaum.

Spinney, L. 2018. Team Building. New Scientist, 237, $38-41$.

Stevens, J. 1996. Applied Multivariate Statistics for the Social Sciences. Mahwah: Lawrence Erlbaum Associates.

Svalestuen, F., Frøystad, K., Drevland, F., Ahmad, S., Lohne, J., dan Lædre, O. 2015. Key Elements to an Effective Building Design Team. Procedia Computer Science, 64, 838-843.

Sweeney, P. J., dan Fry, L. W. 2012. Character Development Through Spiritual Leadership. Consulting Psychology Journal: Practice and Research, 64(2), 89-107.
Thomas, N. 2004. Adair on Teambuilding and Motivation. London: Thorogood Publishing Ltd. Valori, R. M., dan Johnston, D. J. 2016. Leadership and Team Building in Gastrointestinal Endoscopy. Best Practice \& Research Clinical Gastroenterology, 30(3), 497-509.

Vonny, S. A., Mujiati, M., Rosidah, A., dan Gunawan, I. 2017. Gaya Kepemimpinan Kepala Sekolah dalam Perspektif Psikologi. Jurnal Manajemen dan Supervisi Pendidikan, 2(2), 208-217. 